\title{
Assessment Conceptions and Practices: Perspectives of Primary School Teachers and Students
}

\author{
Vera Monteiro *, Lourdes Mata and Natalie Nóbrega Santos \\ Centro de Investigação em Educação, ISPA - Instituto Universitário, Lisbon, Portugal
}

OPEN ACCESS

Edited by:

Chris Davison,

University of New South Wales,

Australia

Reviewed by:

Ibrahim Burak Ölmez, University of Southern California,

Los Angeles, United States

Peter Ralph Grainger, University of the Sunshine Coast, Australia

${ }^{*}$ Correspondence: Vera Monteiro veram@ispa.pt

Specialty section:

This article was submitted to Assessment, Testing and Applied Measurement,

a section of the journal

Frontiers in Education

Received: 19 November 2020 Accepted: 09 February 2021

Published: 07 April 2021

Citation:

Monteiro V, Mata L and Santos NN (2021) Assessment Conceptions and

Practices: Perspectives of Primary

School Teachers and Students.

Front. Educ. 6:631185.

doi: 10.3389/feduc.2021.631185
Students' and teachers' conceptions of assessment are important because they guide how teachers' assessments are implemented in the classroom and determine how students study. This multiple-case design study examined 1) how teachers and students view assessment, 2) how teachers assess their students' learning, and 3) the similarities and disparities that occur when students' and teachers' conceptions and teachers' practices of assessment are compared. Data were obtained from five third grade classes, involving a total of five teachers and 82 students. Data were gathered through individual interviews with teachers and focus group discussions with students. Classroom observations and documents produced by the students (worksheets and tests) during maths lessons were also analyzed. The results of the content analysis of the data indicate that teachers mostly conceive assessment as being for improvement, while their assessment practices and students' conceptions focus on school and student accountability. The results obtained lead us to suggest that students' conceptions of assessment are constructed from their classroom assessment experiences. The study also suggests that teachers adopt conceptions of assessment inconsistent with their practices, that allow them to work within social and contextual constraints.

Keywords: assessment practices, primary school, teacher, students, assessment conceptions

\section{INTRODUCTION}

Classroom assessment has been a topic of interest for researchers in recent years. Focusing on assessment is important for the development of teaching and learning processes. Assessment enables teachers and students to draw inferences from the information obtained and act accordingly. Such actions may aid in making the necessary improvements to teaching and learning, or simply provide a picture in time of students' competence or achievement (Black and Wiliam, 2018).

The study of teachers' and students' conceptions of assessment is an important topic within the domain of assessment research. According to Brown (2008, p. 9), "conceptions of assessment refer to the perceptions people have about assessment, based on their experiences with and of assessment." Teachers' conceptions of assessment are significant because clear evidence exists that these beliefs strongly influence how teachers assess their students' learning and achievements (Vandeyar and Killen, 2007; Brown, 2008; Brown et al., 2009b; Opre, 2015). In addition, conceptions can also influence their classroom practices, such as instructional techniques and motivational strategies (Barnes et al., 2017). Students' conceptions of assessment are also important, since it is known that their beliefs guide and determine how they study (Brown and Hirschfeld, 2007; Brown and Harris, 2012). 
Though this area of research has wide-ranging implications for the teaching and learning process, little is known about the conceptions of students and teachers in primary school, and how these conceptions are related to teachers' assessment practices. Therefore, the primary objective of the present study was to investigate whether primary school students' and teachers' conceptions are aligned with teachers' practices, and to discuss the implications for teaching and learning of this alignment, or its absence.

\section{Teachers' Conceptions of Assessment}

According to Brown (2004, p. 303), "all pedagogical acts, including teachers' perceptions and evaluations of student behavior and performance (i.e., assessment), are affected by the conceptions teachers have about many educational artifacts, such as teaching, learning, assessment, curriculum, and teacher efficacy." It is important to analyze this relationship when teachers' conceptions need to be changed, as in the case of reformulations in a country's education system with consequences for the student assessment system.

In his multiple studies, Brown $(2004,2008)$ found that teachers conceive assessment as having four major purposes. The first conception relies on the idea that assessment improves both teaching and students' learning. Hence, assessment should provide effective feedback, be enjoyable, be felt as something positive that helps students improve, and be inclusive and integrated with the teaching and learning process. A second conception views assessment as making students accountable through scoring, grading, or certification. This means that assessment is used to categorize, differentiate, make social comparisons, and determine whether students have met standards. A third conception views assessment as making schools and teachers accountable, and therefore providing information about the quality of education. The fourth conception relies on the belief that assessment is irrelevant. Here, assessment is seen as inaccurate and bad for students, and is ignored by teachers. In line with this definition of assessment conceptions, Brown (2008) constructed the Teachers' Conceptions of Assessment questionnaire (TCoA).

Research using the TCoA with New Zealand and Queensland primary teachers showed that teachers mostly agreed that assessment improved teaching and learning but disagreed that assessment was for student accountability. They also rejected the conception that assessment was irrelevant (Brown, 2008).

Another approach has been proposed by Remesal (2011), who sees teachers' assessment conceptions as a combination of four aspects: assessment effects on teaching, on learning, on students' certification of learning, and on teachers' accountability. According to the author, assessment can be viewed as being on a continuum with a formative-regulatory pole (pedagogical) and a non-regulatory social pole (societal), and two or three mixed conceptions in between (Brown and Remesal, 2017). When comparing primary and secondary teachers, Remesal (2009, 2011) found that the pedagogical conception of assessment (extreme and mixed forms) predominated among primary education teachers, whereas the accounting conception (societal and accrediting conceptions-extreme and mixed forms) predominated among secondary teachers' conceptions. The author hypothesized that these conceptions could be related to the structure of the educational system and external assessment policy demands in Spain.

Azis (2015) proposed an approach in which conceptions of assessment can be distributed on a continuum of different purposes. At one end of the continuum is Assessment for Learning (AfL), also called formative assessment (Brown and Remesal, 2017), or the pedagogical pole (Remesal, 2007). Here, assessment is aimed at promoting students' learning and providing teachers and students with the information needed to modify teaching and learning strategies (Black and Wiliam, 2018). At the other end of the continuum is Assessment of Learning (AoL), also called summative assessment (Brown and Remesal, 2017), or the societal pole (Remesal, 2007). Here, the focus is on high-stakes accountability, ranking, grading, and/or certification. Between these poles, we find mixed conceptions of the purposes of assessment (Azis, 2015). This approach has some similarities with those of Brown (2004, 2008; Harris and Brown, 2009) and Remesal (2006, 2011). In his article about teachers' conceptions of assessment, Azis (2012) reviewed numerous studies on this subject conducted in six different countries. The results revealed that all teachers believed that assessment improves learning and that assessment relates to school accountability. The author suggested that the six different countries in the review interpret improvement in different ways, being determined by factors such as curriculum level, government policy on education and the experience of teachers.

\section{Students' Conceptions of Assessment}

Much of the research on students' conceptions of assessment has also been conducted by Brown and his colleagues (e.g., Brown and Hirschfeld, 2007; Brown et al., 2009a; Brown and Harris, 2012), primarily with secondary and university students. References to such research with primary school pupils are scarce. This gap in the literature needs to be closed, because what students think about assessment mediates their learning and achievement and has consequences for how they participate in assessment tasks.

A review of the literature on students' conceptions of assessment in general (Brown and Hirschfeld, 2007; Brown 2008; Brown et al., 2009a; Brown and Harris, 2012) identified four different purposes for assessment: 1) improvement: assessment led to improvements in learning and teaching; 2) external attribution: assessment is linked to external attributes of the student, such as their future performance or job, their intelligence, and the quality of the school they attend; 3) affect: assessment has a positive emotional impact on students; and 4) irrelevance: assessment is oppressive, inaccurate, and ignored by students.

Remesal $(2006,2009)$ is one of the few authors to have studied this topic among primary pupils. Based on the categories used to study elementary teachers' assessment beliefs (referred to in the previous section), Remesal (2006) defined three categories of students' conceptions: in the first, students assigned a predominantly regulatory function to assessment; in the second, the predominant function was certification; and in the 
third, the students did not assign any function. The results point to a balancing of the two main assessment functions (regulatory, $44.4 \%$ agreed; certification, $41.7 \%$ agreed), and predominant disagreement with the claim that assessment was irrelevant. Similar results were found with Finnish primary school students (Ämmälä and Kyrö-Ämmälä, 2018). It is apparent from these results that students have multidimensional conceptions of assessment and are aware of them from primary school onwards (Remesal, 2009).

\section{Comparing Teachers' and Students' Conceptions of Assessment}

What students and teachers think and believe about assessment is crucial for the efficiency of the teaching and learning process as well as for a shared understanding of the purposes of assessment in meeting learning and teaching goals. As Andersson (2016) observed, a shared understanding of what is being learning is essential if teachers are expected to help a student learn from their teaching experiences. In teacher-pupil interactions and in peer interactions, knowledge acquisition is dependent on the shared representation that both participants construct of the task and the context in which they are learning. According to Andersson (2016) and Gipps (1999), assessment can be seen as an intersubjectivity setting, where shared understanding between teacher and student is central to learning outcomes. Carless (2009) states that such shared understanding improves the assessment integrity and the quality of the student learning experience. It is therefore important that pupil and teacher conceptions of assessment are aligned.

Few studies have aimed to compare student and teacher conceptions of assessment (e.g., Remesal, 2006; Brown, 2008; Fletcher et al., 2012). Furthermore, these were mostly carried out with secondary or university students.

Remesal (2006) conducted one pioneering study with pupils and their primary school teachers and found differences in their conceptions. Teachers attributed to assessment a function closer to the pedagogical pole, while students presented a more balanced conception of assessment, attributing similar importance to a pedagogical conception and a societal one. Nevertheless, in most cases when pedagogical assessment was mentioned, teachers considered that it serves mostly for teaching improvement, since they believed that students are incapable of participating in the assessment process. The pupils, on the other hand, were of the view that assessment serves to improve not only the teaching but also their learning. They felt it helped them see what they have learned, whether they should try harder, and what they have not understood. According to Remesal (2006), students' and teachers' conceptions are more aligned when they present a pedagogical assessment conception and when teachers make the assessment criteria explicit. The author found more discrepancies when the assessment criteria were not explicit, regardless of teachers' assessment conceptions. Therefore, it seems that the degree to which the assessment criteria are made explicit exerts more influence on students' assessment conceptions than on teachers' conceptions.

The few researchers who have compared the assessment conceptions of teachers and their students have found that, in general, they differ. While students have a clear conception that assessment has a fundamental purpose-the certification of student learning, teachers' conceptions of assessment are not very clear but show a strong tendency toward the purpose of improving teaching and learning. Since teachers and students are directly involved in the same pedagogical process (assessment), it is strange that they perceive it to have different purposes. In this respect, some authors believe that the disparity between teachers' and students' conceptions of assessment may be caused by inconsistencies between teachers' conceptions and assessment practices, with students' conceptions primarily relating to their teachers' assessment practices (Borko et al., 1997; Remesal, 2006). The exceptions to this general trend are the studies by Brown (2008) and Brown et al. (2009b) showing consistency between teachers' and students' conceptions.

\section{Comparing Teachers' Assessment Conceptions and Assessment Practices}

Researchers have shown that the importance of studying beliefs and conceptions is their predictive relationship with practices (Barnes et al., 2015). In the domain of assessment, authors like Brown (2008), Brown et al. (2009), and Vandeyar and Killen (2007) are of the view that teachers' conceptions influence their decisions and professional activities. These authors believe that different assessment conceptions lead to different assessment practices. For example, teachers who conceive of assessment as important for improving teaching and learning will use formative methods of assessment, while teachers who have a conception of assessment for accountability will use summative assessment methods (Vandeyar and Killen, 2007).

Dixson and Worrell (2016) and Siarova et al. (2017) provided a set of characteristics of formative and summative assessment in classroom settings. AoL, also known as summative assessment, has the purpose to evaluate learning outcomes, provides information about student performance, serves to select or group students, and certifies learning and award qualifications. The methods used are projects, performance assessments, portfolios, papers, in-class examinations, standardized tests and national tests. Usually this is done by teachers and students are not active participants in assessment processes. These assessments include mostly closed questions, but they also use extended response items to evaluate how students apply their conceptual understanding and how they think critically, with the final goal of knowing how much a student knows. Summative assessments are graded, not frequent, and occur at the end of segments of instruction.

In contrast, Dixson and Worrell (2016) and Siarova et al. (2017) consider that AfL, or formative assessment, aims to improve students' learning, providing information to teachers and students to be used as feedback to modify teaching and learning. Thus, formative assessment is not usually graded. It can occur in two different practices: spontaneous-for example, 
question-and-answer during instruction in real time-or planned, and it includes activities such as quizzes and homework exercises to assess student progress. Teachers have a key role in providing feedback and information about students' performances, yet the learner is also an important actor in the assessment process. Assessment tools used by teachers, such as observations, homework, feedback sessions, peer tutoring, selfassessment, question-and-answer sessions, comprehensive approaches to teaching and learning, student self- and peerassessment, and effective feedback are frequent. Formative assessment occurs inside the teaching and learning process. The tools support deep learning, develop critical thinking, and promote students' interaction and continuity of the learning experiences (Dixson and Worrell, 2016).

Likewise, in a study with elementary and secondary teachers from Hong Kong, Brown et al. (2009) showed that practices of assessment to improve teaching and diagnose students' learning needs were predicted by the conception that assessment is about improvement. Practices related to preparing students for examination were predicted by the conception that assessments make students accountable. In contrast, findings from other studies (e.g., James and Pedder, 2006; Azis, 2015) have suggested that beliefs and practices of assessment are not related. Azis (2015), who studied the assessment practices and perceptions junior high teachers, noticed a conflict between practices and conceptions caused by the policy requirements of the existing assessment system in Indonesia. Teachers believed that the purpose of the assessment was to improve teaching and learning and to demonstrate the accountability of the students and the school. However, they felt that the state-wide examination policy requirements constrained their efforts to use assessment for these purposes. Hence, teachers' expectations of assessment and government policy were not aligned, causing a conflict between teachers' beliefs and assessment practices.

Similarly, James and Pedder (2006) found among English teachers that participants placed high value on AfL but their practices reflected a greater performance orientation. The authors posited that these results are caused by the testing context in England that required teachers to engage in performanceoriented practices and drive students to achieve in tests. Hence, the value attributed to summative assessment (traditional tests) in teachers' practices is much higher than the value ascribed to this modality in their conceptions when alternative modalities of assessment are highlighted.

These results show that teachers' conceptions are not always consistent with their assessment practices. The relationship between beliefs and practices is real but very complex, and these two elements influence one another (Opre, 2015), depending on individual and contextual factors that interrelate in accordance with each assessment situation (Barnes et al., 2015; Buehl and Beck, 2015). This congruence or incongruence between conceptions and practices has to be taken into account as it has different consequences for teachers' behaviors. According to Buehl and Beck, (2015) teachers' pleasure and wellbeing can be affected by a misalignment and, in extreme situations, teachers may even abandon their profession or implement inappropriate pedagogical practices.

\section{Purposes of the Study}

Authors like Suurtamm et al. (2010) suggest that we need studies to analyze how new ideas about assessment (e.g., AfL) are conceived of by teachers and students and how they are implemented in classroom practice. There have been policy changes within the Portuguese assessment guidelines in the past few decades, some reinforcing an assessment mode that we could call AoL, and sometimes supporting AfL. In the case of mathematics, Nortvedt et al. (2016) observe that, in actuality, assessment guidelines in Portugal are in line with those indicated in international terms (Mullis and Martin, 2015). That is, the regulations emphasize AfL, with a regulatory function over the teaching and learning process, and focus on assessing what is relevant in mathematics - not only what is easy to assess, but also the diversity of forms of assessment (Santos, 2004). Portugal is what the literature calls a low-stakes accountability context for assessment (Barnes et al., 2017). Nevertheless, three years ago there was a proliferation of national exams throughout schooling and frequent summative assessments to motivate students and inform parents, teachers, and schools. Nortvedt et al. (2016) found that, in the Portuguese context, there is a big gap between the curricular guidelines in mathematics and teachers' practices.

Brown (2011) states that teachers develop or adopt conceptions of assessment aligned with their own policy or legal frameworks. So, if teachers' beliefs are related to policies in their professional environment (Brown et al., 2011), teachers in Portugal should mainly possess a conception of assessment that guides improvements in teaching and learning, but also a conception that such assessment serves to judge the quality of student learning (student accountability). Hence, it was important to explore the conceptions that elementary teachers and students currently have about assessment and investigate whether those conceptions are aligned and similar to teachers' assessment practices.

This article presents data on Portuguese students' and teachers' conceptions of assessment and their practices in the domain of mathematics. Based on the research that revealed that teachers' conceptions of assessment differ across contexts and "reflect teachers' internalization of their society's cultural priorities and practices" (Barnes et al., 2015, p. 284), the present study intends to explore Portuguese primary school teachers' and students' conceptions of assessment and teachers' assessment practices and how they are related. Therefore, our research questions were:

1. How do primary teachers and students conceive assessment? Do their conceptions differ?

2. How do these primary teachers assess their students' learning?

3. What are the similarities and disparities that emerge when primary students' and teachers' conceptions and teachers' assessment practices are compared?

\section{The Context of the Study: Assessment in Portugal (First Cycle)}

In Portugal, basic education is compulsory and free. Children have to attend a public or a private school from the age of six 
years. This level of education is divided into three cycles. We focused on the first cycle because there are few studies focusing on assessment conceptions in elementary school. This first cycle has a duration of four years and the components of the curriculum are articulated in a global manner through Grades 1 to 4 . The process of learning and teaching is the responsibility of a single teacher. Assessment is predominantly informal and formative, and assumes a continuous and systematic character aimed at assisting teachers in obtaining all information necessary to implement pedagogical differentiation. Summative tests of educational progress (provas de aferição, external summative assessment) take place at the end of the second grade in mathematics and in the Portuguese language. Their purpose is to monitor the development of the curriculum in different areas and promote timely pedagogical interventions directed to the specific difficulties of each student. Yet seems to us to be an accountability purpose to the system and to the school, and results are reported to parents, teachers, and schools. Internal summative assessment occurs at the end of each trimester, with the purpose of classifying and certifying student progress or retention (Decreto-Lei 55/2018 de 6 de julho, 2018).

\section{METHODOLOGY}

\section{Participants}

Four schools were selected for this study, based on purposive sampling (Etikan et al., 2016). The main reason for choosing these schools was the possibility of experimental mortality. Data collected for this multiple-case study were part of a broader longitudinal research project that intended to understand the effects of teachers' assessment on students' achievement, motivation, and emotions. For the purpose of this project, it was necessary to ensure that students remained in the same school with the same teacher two years. This prerequisite was taken into account when selecting schools for this study. Once the schools were selected, our data were collected over two years. The data presented in this study refer to the first year.

Five teachers teaching third grade classes (A, B, C, D and E) and 82 students (between 11 and 23 students per classroom) participated in this study. Teachers (one male and four females) had between three and 25 years of experience. Students were aged $7-10$ years $(M=8.07, S D=$ 0.34); 47 were boys and 35 girls.

\section{Data Collection and Analysis}

The data were gathered through individual interviews with teachers and focus group discussions with students, both of which were held at the end of the school year. Classroom observations and documents produced by the students (worksheets and tests) were also analyzed to determine teachers' assessment practices. Data collected were related to the domain of mathematics, a core subject in school education, which has high failure levels among Portuguese students (Organization for Economic Co-operation and Development, OECD, 2016).

\section{Procedures to Classify Conceptions of Assessment}

In order to understand teachers' and students' conceptions of assessment, one of the authors conducted semi-structured individual interviews with the teachers while another conducted focus group discussions with groups of four to five students. A total of 16 focus groups were conducted (two groups for Class D, three groups each for Classes B and A, and four groups each for Classes $\mathrm{C}$ and $\mathrm{E}$ ). Groups were mixed gender and were defined through random sampling. The focus group started with the researcher trying to create a friendly environment, explaining the purpose of the study and giving time for the students to ask questions. The moderator ensured the participation of all members and kept the discussion informative rather than argumentative. The objective was not to reach a consensus but to collect all students' opinions.

Both interview and focus group questions were based on the literature (Remesal, 2006; Azis, 2015) and addressed five assessment topics for the teachers and four for the students (see Table 1). The same interview protocol was used in all the interviews and focus groups to ensure methodological consistency and control for reliability (Cohen et al., 2008). The content validity and appropriateness of the interview questions were verified by an expert in educational psychology.

All individual interviews and focus group discussions were audio-recorded and transcribed verbatim. Two of the authors performed a content analysis using the software MAXQDA 18. The interview and focus group contents were coded into fragments describing different categories, which were defined using both deductive and inductive approaches. Starting from the categories previously described by Brown (2008) and Harris and Brown (2009), the categories were progressively redefined through a cyclical process in order to fit and be representative of the reality of our data (Miles et al., 2014). Four qualitatively different categories of assessment conception were identified: external reporting, students' accountability, external motivation of students, and improvement of learning and teaching (see Table 2).

Intracoder consistency was assessed six months after the first analysis, with $84.6 \%$ agreement (mean $\kappa$ for the categories was 0.925 , between 0.894 and 0.953 ). For intercoder consistency, a second coder, working as a supervisor, confirmed the analyses of the first coder. Deviations from the initial analysis were discussed with all authors until final agreement or eventual recategorization.

\section{Procedures to Classify Assessment Practices}

Data about the teachers' assessment practices were gathered through the video recording of all the lessons in two learning units in the mathematics domain (one in the winter about stem and leaf diagrams and one in the spring about addition and subtraction with decimal numbers). We videotaped the teachers as they delivered regular lessons in the selected units, which varied in number (between three and eight sessions) and in duration (between 30 and $120 \mathrm{~min}$ ). We also gathered all documents produced by the students during the lessons (worksheets, textbooks, notebooks, etc.). A total of 24 lessons 
TABLE 1 | Topics and questions of the semi-structured interview protocol.

\begin{tabular}{|c|c|c|}
\hline Topics & Questions for teachers & Questions for students \\
\hline $\begin{array}{l}\text { A. General assessment } \\
\text { definition }\end{array}$ & For you, what is assessment? & $\begin{array}{l}\text { You get assessed in school. If you had to explain to someone what } \\
\text { assessment is, what would you say? }\end{array}$ \\
\hline B. What to assess & $\begin{array}{l}\text { What do you assess in math in grade } 3 \text { in these different situations? Is } \\
\text { the assessment same or different? } \\
\text { If it is same, what do you assess? } \\
\text { If it is different, what do you assess in each type of situation? }\end{array}$ & \\
\hline C. The intent of assessment & $\begin{array}{l}\text { Why do you assess your 3rd graders? } \\
\text { What is the need for these math assessments? }\end{array}$ & $\begin{array}{l}\text { Why is your teacher assessing you in math? } \\
\text { What is the assessment for? }\end{array}$ \\
\hline D. Assessment process & $\begin{array}{l}\text { Who does the assessment in mathematics? When do you assess? } \\
\text { What assessment methods do you use with your 3rd graders? }\end{array}$ & $\begin{array}{l}\text { Who does the assessment in mathematics? } \\
\text { When does your teacher assess? How does your teacher } \\
\text { assess you? }\end{array}$ \\
\hline $\begin{array}{l}\text { E. Use of the information } \\
\text { from assessment }\end{array}$ & $\begin{array}{l}\text { How can you and your students use the information from the different } \\
\text { assessment tasks in maths? At the end of the trimester, what factors } \\
\text { do you consider when assessing your students? }\end{array}$ & $\begin{array}{l}\text { In the worksheets/tests does the teacher write anything? What do } \\
\text { you do with the information you receive? In class when answering } \\
\text { questions asked by the teacher, does she make comments? What } \\
\text { kind of comments? What do you do with the comments the teacher } \\
\text { makes to your answers during class? }\end{array}$ \\
\hline
\end{tabular}

TABLE 2 | Categories mentioned in the interviews and focus groups.

Categories

1. External reporting - assessment as a useful tool for reporting students' performance to parents, ministries, and schools.

2. Students' accountability-assessment is used by students and teachers to evaluate students' performances, to indicate where they are in terms of learning and knowledge.

3. Extrinsically motivating students-assessment is described as a way of motivating students through competition, social pressure, or praise.

4. Improvement of learning and teaching - assessment is considered an important element in learning, knowledge, and teaching.

Note. $A, B, C, D$, or $E=$ Classes $A, B, C, D$, or $E ; S=$ Students; $T=$ Teacher

were videotaped $(1,767 \mathrm{~min})$, and 860 documents (with 3,044 questions/exercises) were analyzed.

The qualitative data were analyzed using an observation grid derived from the literature about summative and formative assessment practices (Hattie and Timperley, 2007; Dixson and Worrell, 2016; Siarova et al., 2017; Singh et al., 2017). The dimensions observed are described in Table 3.

For the analyses of the dimensions oral questioning, type of question, who initiated the oral interactions, and oral feedback, we selected segments of video data for every teacher for closer analysis. These segments were the first moment of instruction, the last moment of individual work with textbooks or worksheets, and a moment when students worked in small groups. Two types of interaction (teacher initiation/student(s) response/teacher's feedback and student(s) initiation/teacher's feedback) were assessed for a maximum 30-min segment for each moment. In total, we examined 24 segments, being $680 \mathrm{~min}$ of footage, and observed 1,675 interactions. The proportion of these interactions did not differ significantly among the classes $(z$-test $p>0.050)$. Descriptive statistics of all the categories of the observed dimensions of assessment practices, such as relative percentages, were calculated to check through the data rapidly and protect against bias (Miles et al., 2014). These descriptive statistics were used to differentiate and characterize formative and summative practices for each of the dimensions observed, according to the theoretical basis described in Table 3.

Intercoder and intracoder reliability (four months apart) were excellent, with an observed agreement of $94.7 \%(\kappa=0.78)$ and 94.5\% $(\kappa=0.80)$ for intracoder reliability, and $91.5 \%(\kappa=0.72)$ and $91.8 \%(\kappa=0.70)$ for intercoder reliability.

\section{RESULTS}

The dataset obtained in this study was very large and complex in nature. Here we present a selection of the main analysis 
TABLE 3 | Dimensions and categories of analysis for the assessment practices.

Dimensions

1. Who evaluates

2. Who initiated the oral interactions

3. Oral questioning: Who is questioned

4. Assessment tools used

5. Oral questioning: Type of question

6. Written questioning: Level of cognitive complexity

7 and 8. Oral and written feedback (Focus)

\section{Categories}

1.1. Teacher assessment

1.2. Peer assessment

1.3. Self-assessment

2.1. The teacher, by asking questions

2.2. The students, by asking questions or making statements to obtain feedback

3.1. All students (or almost all students) are questioned

3.2. A few students (mostly the same ones) are questioned

4.1. Worksheets developed by the teacher

4.2. Worksheets from a textbook

4.3. Classroom observation

4.4. Group work

4.5. Homework

4.6. Oral presentations

4.7. Checking daily notebooks

5.1. Open

5.2. Closed

6.1. Low-remember (focus on retrieving relevant knowledge from long-term memory) and understand (focus on clarifying, recalling, naming, and listing)

6.2. High - apply (focus on prior knowledge to solve a problem), analyze (focus on carrying out a procedure in a given situation) and evaluate (focus on making judgments based on criteria and standards)

7.1. Feedback at the self-level (praise or criticism without task-related information)

7.2. Feedback at the task and product level (corrective feedback, pointing out errors or providing correct forms)

7.3. Feedback at the process level, aimed at the processes used to complete the tasks (clarifications, hints, suggestions for the future, or asking for explanations)

7.4. Feedback at the self-regulation or conditional level, which engages students' skills in self-evaluation (encouraging self-assessment)

TABLE 4 | Overview of students and teachers' assessment conceptions.

\begin{tabular}{|c|c|c|c|c|c|c|}
\hline \multirow[b]{2}{*}{ Criterion } & & \multicolumn{5}{|c|}{ Classes } \\
\hline & & A & B & C & D & $\mathbf{E}$ \\
\hline \multirow[t]{2}{*}{ Categories most often covered } & Teacher & ILT & $\mathrm{ILT}$ & ILT & ILT & ITL \\
\hline & Students & ITL & SA & SA & SA & SA \\
\hline \multirow[t]{2}{*}{ Categories where several different aspects were mentioned } & Teacher & ILT & ILT & ILT & ILT & $E R \& S A \& I T L$ \\
\hline & Students & SA \& ILT & SA & SA & SA & SA \& EMS \\
\hline \multirow[t]{2}{*}{ Categories mentioned in (nearly) all the interview topics } & Teacher & SA \& EMS \& ITL & ILT & ILT & SA \& ILT & SA \\
\hline & Students & SA \& ILT & SA \& ILT & SA \& ILT & SA & SA \\
\hline
\end{tabular}

Note. $E M S=$ Extrinsically motivating students; $E R=$ External reporting; $I L T=I m p r o v e m e n t$ of learning and teaching; $S A=S t u d e n t s '$ accountability;

categories. We first summarize teachers' and students' conceptions of assessment, and teachers' assessment practices. Then we compare and contrast their conceptions and teachers' assessment practices in more detail.

\section{Teachers' and Students' Conceptions of Assessment}

Teachers and students mentioned all four categories during the interviews. In Table 4, we summarize for each teacher and for their students the categories most often covered, the categories with richer content (i.e., several different aspects of the category were mentioned), and the categories mentioned in nearly all the interview topics. This information allowed us to order our participants along the continuum ranging from the AoL pole (with greater focus on certification and accountability) to the AfL pole (with greater focus on improving learning and teaching). Most of the students seemed to be predominantly at the AoL pole of the continuum, while most of the teachers were at the AfL pole (see Figure 1).

Teachers $\mathrm{B}$ and $\mathrm{C}$ mentioned the improvement of learning and teaching many times; they mentioned several different aspects of this category, and also mention it, throughout the entire interview (See Table 4). Teachers' B and C discourse indicated that their conception of assessment was largely focused on improving students' learning, closer to the AfL pole (see Figure 1). Teachers A and D had mixed conceptions, having highlighted assessment for learning as the purpose of assessment but also constantly mentioning throughout the interview the students' accountability and extrinsically motivating students as important purposes of assessment. Finally, Teacher E also had a mixed conception, yet it was closer to the AoL pole. Teacher E 


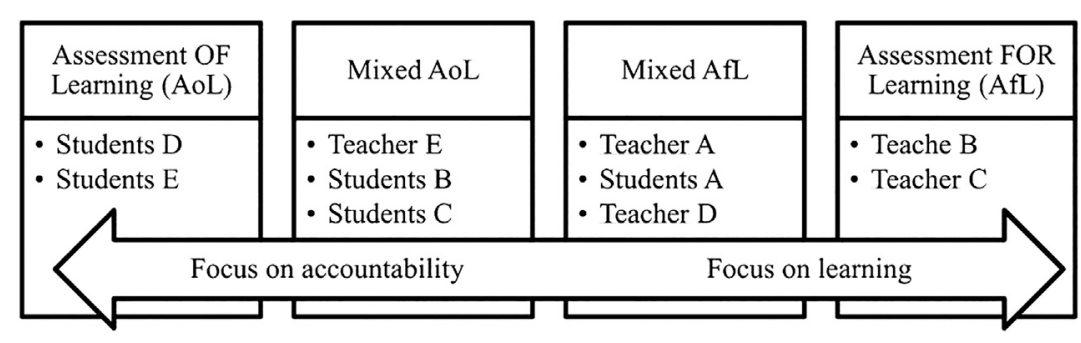

FIGURE 1 | Description of the Conceptions of Teachers and Students.

mentioned the improvement of learning and teaching more times than any category, but her discourse was very rich about external reporting and students' accountability, mentioning different aspects of these categories. Improvement of learning and teaching was mostly mentioned when taking about feedback, while students' accountability was mentioned throughout all topics of the interview (see Table 4). Therefore, this teacher also focused on improving teaching and learning, but emphasized external reporting and students' accountability as the primary purpose of assessment, while considering that only feedback had the purpose of improve learning and teaching.

In contrast, most of the students in all classes considered the primary function of assessment to be verifying the correct answer. Most of the comments related to the improvement of learning and teaching purpose were offered only when the topic of oral feedback was questioned, while students' accountability was mentioned throughout all topics (see Table 4). Students in classes $\mathrm{B}$ and $\mathrm{C}$ presented a mixed conception, but with a stronger presence of an AoL conception. Only the students in Class A presented a mixed conception more focused on AfL, mentioning the improvement of learning category several times; the category was broken down into several different aspects and mentioned in most of the interview topics. Students from classes $\mathrm{D}$ and $\mathrm{E}$ mentioned students' accountability more times, using a very rich discourse (they mentioned several aspect of this category) and mentioning it throughout the interview. Hence, we considered that students of Teachers D and E presented an AoL conception.

\section{Teachers' Assessment Practices}

The structure of the mathematics lessons delivered by these five teachers was uniform and followed the following sequence:

- Instruction: the teacher introduced content that students had not previously worked on by using expositions, demonstrations, illustrations, problem-solving and class discussion. In these moments, the most used assessment tool was oral questioning, used mostly for certification of previous knowledge.

- Practising the new content: students practised or applied the newly introduced content through individual or group tasks, mostly using worksheets developed by the teacher or from textbooks. In these moments, the assessment tool more used was classroom observation without keeping a record. The feedback used in these moments was more focused on the process, but most feedback was still at the level of the task.

- Formal assessment: Teacher assessed mostly by checking the answers to the exercises completed during the practice moments through oral or written feedback. Most of the feedback given in these moments was corrective.

Based on the analysis of the different moments of the lessons observed in the sample, all teachers presented mixed assessment practices (see Table 5), with a tendency to use summative assessment in more dimensions, closer to an AoL pole. Teacher E consistently presented very few AfL practices.

\section{Analyzing Conceptions and Practices}

This section presents a more detailed description of the data concerning teachers' conceptions of assessment and their practices. The objective was to find similarities and discrepancies between teachers' assessment conceptions and their practices and to reflect on the effects of teachers' conceptions and practices on students' conceptions.

\section{Looking at Teachers B and C and Their Students}

Though Teachers B and C both presented an AfL conception, they still showed some particular differences. One was related to the focus of the improvement. Teacher B was more focused on improving teaching and considered assessment important for modifying teaching strategies for the benefit of students (e.g., "If I see that a large majority of the group failed in a particular subject, then I see that this issue has to be... taken up in a different way because it was not assimilated as I thought it should be"). Teacher $\mathrm{C}$ focused more on improving students' learning through their self-regulation. For her, the purpose of assessment was to identify students' weaknesses, foster students' self-regulation skills, and provide for individual needs. This purpose was borne by this teacher's understanding of AfL: "The assessment process is discussed with them [students]... It is work that is done together, me and the students... they plan what they want to work on... after realizing the difficulties of the students, I try to meet the needs of each one."

These teachers also differed in their conceptions of feedback. When questioned about feedback, the teacher of Class C emphasized the importance of ensuring that the student understood and agreed with the assessment (e.g., "When there is something negative, I ask, 'Do you agree with what I wrote or 
TABLE 5 | Overview of teachers' assessment practices.

\begin{tabular}{|c|c|c|c|c|c|}
\hline \multirow[b]{3}{*}{ Dimension } & \multicolumn{5}{|c|}{ Description of teachers' assessment practices } \\
\hline & \multicolumn{5}{|c|}{ Classes } \\
\hline & A & B & C & D & $\mathbf{E}$ \\
\hline \multirow[t]{2}{*}{ 1. Who evaluates? } & $100 \%$ & $100 \%$ & $60 \%$ Teacher $+40 \%$ & $100 \%$ & $100 \%$ \\
\hline & Teacher & Teacher & Peer assessment & Teacher & Teacher \\
\hline \multirow{5}{*}{$\begin{array}{l}\text { 2. Who initiated the } \\
\text { interactions } \\
\text { 3. Oral questioning - who } \\
\text { is questioned } \\
4 . \text { Assessment tools } \\
\text { used }\end{array}$} & $39.4 \%$ & $56.1 \%$ & $45.6 \%$ & $37.9 \%$ & $29.8 \%$ \\
\hline & Students & Students & Students & Students & Students \\
\hline & $33.3 \%$ & $0 \%$ & $50 \%$ & $50 \%$ & $20 \%$ \\
\hline & All students & All students & All students & All students & All students \\
\hline & $\begin{array}{l}\text { - Worksheets } \\
\text { developed by the } \\
\text { teacher } \\
\text { - Group work } \\
\text { - Observation }\end{array}$ & $\begin{array}{l}\text { - Worksheets developed by } \\
\text { the teacher and from } \\
\text { textbooks, } \\
\text { - Observation } \\
\text { - Group work }\end{array}$ & $\begin{array}{l}\text { - Worksheets } \\
\text { developed by the } \\
\text { teacher, } \\
\text { - Observation } \\
\text { - Oral presentation } \\
\text { - Group work }\end{array}$ & $\begin{array}{l}\text { - Worksheets developed by } \\
\text { the teacher and from } \\
\text { textbooks } \\
\text { - Observation } \\
\text { - Oral presentation } \\
\text { - Group work }\end{array}$ & $\begin{array}{l}\text { - Worksheets developed by } \\
\text { the teacher and from } \\
\text { textbook } \\
\text { - Observation }\end{array}$ \\
\hline \multirow{7}{*}{$\begin{array}{l}\text { 5. Oral questioning - kind } \\
\text { of question used } \\
\text { 6. Written questioning } \\
\text { Cognitive level } \\
\text { 7. Oral feedback (Focus } \\
\text { level) }\end{array}$} & $82.7 \%$ & $80.1 \%$ & $74.0 \%$ & $66.3 \%$ & $94.1 \%$ \\
\hline & Closed & Closed & Closed & Closed & Closed \\
\hline & $63.2 \%$ & $55.5 \%$ & $31.9 \%$ & $59.3 \%$ & $63.9 \%$ \\
\hline & High & High & High & High & High \\
\hline & $5.5 \%$ Self & $16.1 \%$ Self & $6.3 \%$ Self & $8.5 \%$ Self & $5.2 \%$ Self \\
\hline & $55.9 \%$ Task & $52.1 \%$ Task & 69.9\% Task & $50.8 \%$ Task & $71.4 \%$ Task \\
\hline & $38.6 \%$ Process & $31.7 \%$ Process & $23.8 \%$ Process & $\begin{array}{l}\text { 40.3\% Process } \\
0.4 \% \text { Self-regulation }\end{array}$ & 23.3\% Process \\
\hline \multirow{3}{*}{$\begin{array}{l}\text { 8. Written feedback } \\
\text { (Focus level) }\end{array}$} & $0 \%$ Self & $5.5 \%$ Self & $2.7 \%$ Self & $14 \%$ Self & $1.8 \%$ Self \\
\hline & 98\% Task & 80.0\% Task & 91.1 Task & 84.1\% Task & $91.6 \%$ Task \\
\hline & $2 \%$ Process & $14.5 \%$ Process & 6.1\% Process & $1.8 \%$ Process & 6.6\% Process \\
\hline
\end{tabular}

what I said?' and they actually say 'Ah! Yes, I could have tried harder. You're right'. And that's it. And indeed, then there is. . a return. They make the effort to be more aware, more focused"). This teacher considered this agreement very important because students used that feedback to plan their learning (e.g., "In the following week, in their Individual Work Plan, they paid attention to everything that had been transmitted by me, whether oral or written"). Teacher B highlighted the use of feedback only for general encouragement (e.g., "For example, when there is a kid who is systematically failing an account, day by day, when he finally succeeds, I say 'Hallelujah!'”)

Contrary to their assessment conception being very focused on the improvement of learning and teaching, the assessment practices of Teachers $\mathrm{B}$ and $\mathrm{C}$ were mostly mixed. Teacher $\mathrm{C}$ presented mixed practices, close neither to the AfL pole nor the AoL pole. Overall, it was she who evaluated the students, but she sporadically facilitated peer evaluation. She used alternative student-centred assessments (specifically, peer assessment) in each unit that was observed. She encouraged her students to initiate interaction related to the topics that they were studying (Table 5). She also used a wide variety of tools to acquire information about students' knowledge. All these practices are used when the teacher's purpose is to increase students' learning (Cizek, 2010). However, she posed several closed-ended questions at a low cognitive level and provided students with correct answers, using very summative feedback. The sheets and tests used by the teacher posed low cognitive level questioning (only $31.9 \%$ of the questions were from the applying or analyzing level), which do not help students increase autonomy (Singh et al., 2017). She largely provided task-related oral and written feedback, and this practice was incongruous with her beliefs that focused on students' self-regulation. There was little room for process-related feedback when the questions focused on low cognitive levels.

Teacher B's classroom assessment practices also diverged from her AfL conception of assessments. On the one hand, observations of her assessment practices confirmed that she was the only evaluator across all the lessons. Teacher B used closed-ended questions more frequently than open-ended questions, questioning only a few students-usually those who volunteered. Most of the oral feedback provided during this process focused on the task and on providing the correct answer (See Table 5). Furthermore, a significant percentage of the feedback also focused on the self $(19.2 \%$, the highest rate of all teachers), offering general encouragement to students, as indicated in the interview, but with little effect on students' learning (Hattie, 2012). Written feedback was mostly provided in relation to formal assessments for verification purposes, even though Teacher B provided a higher percentage of process-related feedback (12.9\%) than other teachers. On the other hand, Teacher $B$ created a supportive environment within which the students felt comfortable enough to express their thoughts and ideas. Indeed, this was one of the classes in which students tended to initiate more interactions (Table 5). Written questions primarily pertained to understanding and application cognitive levels, and some questions pertained to the analysis level. This was indicative of the use of high-level questioning. She used different classroom tools to collect information during individual and group work (questioning, observation, evaluation sheets, projects, and tests). 
The influence of accountability on students' thinking was common among students from classes B and C; both showed a mixed conception of assessment, closer to the AoL pole. Students' conceptions from both classes were more consistent with their teacher's practices than with their teachers' conceptions. For these students, assessment primarily fulfilled a social function of certification of their knowledge and served to regulate learning minimally; as such, it appeared to be a process controlled mostly by their teachers. Students often stated that assessment was the process of checking their work (e.g., "Assessment is something that, when you do something wrong, your teacher says to you, 'Oh, this is not ok!', and when you understand and you do well the teacher says: 'Ah! Very well, now you understand"'). When questioned about the type of feedback provided by the teacher, they mentioned verification (at task level or the self-level), such as "good girl" or "great effort." This was coherent with the type of feedback they received from their teacher. The triangulation of our findings from teacher interviews, classroom observations and student focus groups revealed that these teachers' vision of assessment was for improvement, even though their actual assessment practices (especially feedback practices) were coherent with students' conceptions that assessment should hold students accountable for learning.

\section{Looking at Teachers $A$ and $D$ and Their Students}

Teachers A and D presented a mixed conception, closer to the AfL pole. While assessment fulfilled a primarily formative function for these teachers, it was also considered important to establish common minimum levels that all students must achieve. In their interviews, these teachers focused mainly on the improvement of learning and teaching [e.g., "I assess the students every day, their evolution, you see? Then I know, 'I need to work more with that student' (or) 'He needs one more exercise, more training"' - Teacher D]. Based on students' performance in evaluation tests, the teachers realized that some content had not been learnt well and tried to fill this gap by adjusting their teaching and providing learning guidance. Nevertheless, a certification purpose was present in their conception of assessment (e.g., ". . . . until some day, they had to know, and that's it. They really have to know. If they do not know, they have a 'wrong"' - Teacher A). Teacher A highlighted the importance of assessment for students' academic and professional futures, for preparing students for future assessments, and for developing the skills needed in "real life":

“... thus, throughout our life, we are always being assessed, aren't we? By other people's opinions or by our performance at work. We are always being evaluated. Children need to realize that, sometimes, they have to be assessed in a more formal or informal way. It is important that they learn how to react when they are assessed, isn't it? (Teacher A)."

In this regard, assessment is considered a pre-requisite for students to be prepared for the social challenges of everyday life. In turn, Teacher D emphasized the verification of students' current knowledge (e.g., "When I use assessment it is to appraise their knowledge") and feedback consisted of information to students about progress, but at the task level (Hattie and Timperley, 2007) (e.g., "I think feedback should be used to tell my students how well they are performing in school and if what they are doing is correct or not").

Teacher A presented mixed assessment practices, closer to the AoL pole. Here, the teacher controlled all the assessment processes. She was the only evaluator across all the lessons that were observed. Most of the interactions were initiated by the teacher. The main assessment mode used by this teacher was oral questioning, addressed to the entire class, but only a few students participated, and it was the same students who typically volunteered to answer. Most questions were closed-ended, which seemed to indicate that the purpose of these questions was to evaluate students' level of understanding of the unit content. In contrast, the written questioning used by the teacher concentrated on the use of highlevel questioning, but Teacher A neither checked the work completed by the students nor worked out the solutions on the blackboard, which meant that little feedback was offered to the students. The little feedback offered was almost always focused on the task, although some oral feedback also focused process (38.6\%; see Table 5). In sum, Teacher A evaluated only certain aspects of the learning process, evaluated students' prior knowledge, and corrected errors. These summative practices hold students accountable for the concepts that they learn.

However, students' and teachers' in Class A were aligned in their mixed conception closer to the AfL pole, which was inconsistent with the teacher's greater accountability practices. These students highlight the importance of assessment for their learning and teaching (e.g., "The assessment is for the teacher to help us when we have some difficulty. For example, the teacher provided some extra classes, talked to our parents to explain the situation, assigned more homework, or spent more time to try to find a solution... That's what the assessment is for: to know what we know, what we do not know, and what our difficulties are"). Just like their teacher, students in this class often stated (more than those of other classes) the importance of assessment for their future (e.g., assessment is “. . . for the future, for when we go to work... imagine, if the teacher does not evaluate us, in the future we do not have a good job"), reflecting ideas expressed by the teacher during the interview.

Teacher $\mathrm{D}$ valued the formative and summative purposes of assessment and sought to achieve synergy during the assessment process. This conception of assessment was consistent with her assessment practices. In Class D, assessment was controlled by the teacher, and most of the interactions established between teacher and students, two-thirds of the observed interactions, were initiated by the teacher. Furthermore, the oral questions that were posed to the students were largely closed-ended. However, one-third of them were open-ended questions and the teacher used them to promote student learning. The feedback provided to the students (written and oral) focused largely on the task. However, oral feedback at the process level was provided to a slightly greater extent to support and guide students. Moreover, Teacher D was the only teacher that offered feedback at the self-regulated level (See Table 5). To gauge and guide student learning, several different assessment tools were used. 
In contrast to these more formative practices and to their teacher's conception, students presented a conception very close to the AoL pole. Only one focus group mentioned learning as a purpose of assessment, but with the final purpose of "progressing well to the fourth grade." The high degree to which students in Class D endorsed the accountability purposes of assessment seems to be more consistent with some summative assessment practices embedded in their teacher's activities. Teacher D checked the work completed by each student at the end of almost every lesson and provided written feedback (which focused largely on the task and aimed to check the correctness of students' answers). She always provided the final written evaluation (a symbol, which indicated that the answer was correct) only after the students successfully completed their task: hence all the tasks completed by the students were marked as having been completed correctly. Consequently, for these students, assessment happened when the teacher checked the answer, which is mostly necessary to set minimum standards that all students must meet to be promoted to the next school year (e.g., "I think it serves so we feel... so we know, that we did 'good'... that we did a good job and... that we are ready for fourth grade and so on."). These students had little concern for improving learning. It was more important that all students achieved the pre-defined objective: "Assessment is important to the teacher to know if we have mastered the contents so that we can progress to a higher grade."

\section{Looking at Teacher E and Her Students}

Teacher E presented a mixed conception of assessment. When talking about assessment, Teacher $\mathrm{E}$ was focused on the certification of learning, specifically external reporting [e.g., assessment is done because "parents required (me) to do it"] and students' accountability (i.e., the main purpose is to summarize student achievement: “. .for me, assessment is done based on percentages attributed to each performance criterion: $30 \%$ from formal assessment and 70\% from informal assessment"). On the other hand, for this teacher, the feedback should be focused on the process for it to be an important tool for teaching and learning ("The main goal in assessment is that children realize what they actually did wrong. . . that students engage in error correction strategies following error detection and that they strive to improve their learning. The important thing is for them to understand that if they fail, they can seek help").

Teacher E presented mostly AoL assessment practices. Teacher E played a substantial role in student assessment. She was the only evaluator across all the lessons, and classroom interactions were dominated by this teacher: only one quarter of the interactions were initiated by the students. Almost all the oral questions were closed-ended, and her feedback focused largely on the task. She did provide process-related feedback, but only when oral questioning was conducted (See Table 5). Written questions pertained to the lower cognitive levels. There was no concern on the part of the teacher about incentivizing all students to participate actively in classes. The tools that this teacher used to evaluate students' learning (questioning, observation, textbook exercises, worksheets and tests) were designed to be used individually. Teacher $\mathrm{E}$ checked the work completed by each student at the end of almost every lesson and provided written feedback to verify the correctness of their answers.

Teacher E's practices and conceptions were reflected in the students' conceptions, presenting an AoL conception. Students emphasized that assessment was mostly necessary for assigning grades, categorizing students and determining if students can be promoted to the next grade. Both teacher and students mentioned the importance of assessment to motivate students to achieve the "honor roll," a prize given for the best students (e.g., "The assessment allows us to get awards and go to the honor roll”). Students also consider that without assessment, they will not even try to learn (e.g., students mention that "if there is no assessment, there is no point for me doing the worksheet," while the teacher said: "They know that this trimester they will not be assessed in the science class, so the kids are totally careless... they are not that careful as when they know they will be assessed-'I will be evaluated, I need to pay some attention'”).

\section{DISCUSSION}

In the present study, we first aimed to investigate the classroom conceptions of five primary teachers and their students' assessment conceptions. Our analysis resulted in four categories which ranged from completely focused on accountability to focused on learning. There was variation in how teachers and students conceived assessment. Nevertheless, our analysis revealed no consistency between the conceptions of students and teachers except for Teacher A and her students.

On the one hand, the findings revealed that teachers believed assessment was mainly intended to improve learning and teaching (pole AfL). These results are similar to those obtained by Remesal (2009, 2011), where primary teachers revealed a pedagogical conception of assessment, in extreme and mixed forms. These outcomes are also in line with the Portuguese assessment guidelines (Decreto-Lei 55/2018), which indicate that assessment in the first cycle of schooling should help teachers and students to improve teaching and learning-that is, help students to perceive what they should improve upon and how, and help teachers adjust their pedagogical strategies to students' needs. This conception meets Black and Wiliam (2018) definition of formative assessment. These findings are important because, according to the studies of Brown (Brown, 2008; Brown et al., 2009b), teachers' conceptions influence their decisions in the classroom. Given this argument, it is expected that these teachers will use formative assessment approaches and techniques to better understand students' learning needs and adjust their teaching strategies to promote students' achievement.

On the other hand, the results also illustrated that the students' conceptions of assessment stood at the AoL pole (extreme or mixed forms), with a strong emphasis on summative assessment. Only the students in one class (Class A) revealed a mixed conception closer to AfL, similar to their teacher's conception. These results provide evidence that, from the time these children went to primary school, they agreed less with an improvement conception of assessment, in contrast to the results obtained by 
Harris and Brown (2009). These results are important because some researchers (Brown and Hirschfeld, 2007; Harris and Brown, 2009) state that students' conceptions of assessment guide and determine how they study. Therefore, our findings reflect that for these young students (about eight years old) assessment is "high stakes" in driving their study behavior toward grades. There is a clear and unambiguous consequence to students based on their grades. These beliefs are congruent with the purposes of summative assessment, in that assessment should be used to measure students' learning at the end of a unit, to promote better learning outcomes, to get a certification for school completion, or to select students for entry into further education (Organization for Economic Cooperation and Development, OCED, 2008).

When comparing the conceptions of these teachers and students, our results differed from those of Brown (2008, 2012) and Brown, Irving, et al. (2009), and were similar to the results from Remesal (2006). Probably, as observed by Borko et al. (1997), the disparity between teachers' and students' conceptions could have resulted from the discrepancy between teachers' conceptions and their practices. Indeed, our results showed an inconsistency between teachers' conceptions and practices, and more coherence between teachers' practices and students' conceptions. This allows us to think that these teachers' assessment practices may in some way contribute to the way their pupils conceive the assessment process. This reinforces the socio-constructivist point of view that conceptions of assessment are social constructs that depend on the pedagogical experience and the environment in which teachers and students are involved (Gipps, 1999).

Our analysis also focused on teachers' assessment practices and on the relationship between teachers' conceptions of assessment and their assessment practices. Our analysis revealed low consistency between conceptions and practices, though there was one exception, Teacher E. Most teachers use summative assessment practices and emphasize the measurement of learning and control of the assessment process, using feedback at the task level. Furthermore, in the observed lessons and documents, the teachers provided students with little effective oral feedback and when it did occur it was mainly at the task level. Still, teachers rarely provided written feedback at process level; they mostly gave grades that did not reveal the real needs of students. Thus, the results of the present study showed that these teachers used assessment mostly to measure the reproduction of knowledge (most questions were from a low cognitive level). The teachers probably wanted to ensure that their students reached a level of success or proficiency necessary to enter the second cycle of studies.

Accordingly, based on the statement that assessment guides students' learning and competences for learning, our results suggest that the assessment practices of these teachers should be carefully considered. Peer assessment was mentioned by only one teacher and self-assessment was not mentioned at all. However, these assessment methods are increasingly important for dialogical teaching and learning, where formative assessment takes on a very relevant role. The assessment practices applied by the teachers participating in the present study seem not to guide students' learning.
The results of the present study indicate that, at least in circumstances such as those observed in these five teachers, the teachers' conceptions are not consistent with their teaching practices. In our study, only one teacher (E) showed consistency between conceptions and practices. She conceived assessment as a mean of measuring factual knowledge and she adopted mostly summative assessment practices.

Contrary to the results obtained by Brown (2008), Brown, Irving, et al. (2009), and Vandeyar and Killen (2007), which concluded that the conceptions that teachers have about assessment influence their practices, we found in the present study that their practices did not always reflect their beliefs. Some factors may explain these discrepancies between our results and past findings.

One set of explanations relates to the nature of the methods used. The current study specifically focused on qualitative data, while Brown's studies (2008, 2012; Brown et al., 2009a) worked with self-administered questionnaires with closed-ended rating scales and statistical data. There are strengths and weaknesses to these two crucial research paradigms in education, qualitative and quantitative. Nevertheless, we highlight the benefits of using qualitative research in the assessment domain. Qualitative approaches allow us to achieve a more profound understanding of the data gathered in all phases of the process (Rahman, 2017); it is easier to understand the behavior of the participants, the interviewees, and the contextual and socio-cultural influences on the behavior of participants during interviews. Of course, there are some limitations, such as small sample size, which make the results unreliable and ungeneralizable and hence not preferred by policymakers (Rahman, 2017).

Another explanation is related to the Portuguese guidelines on assessment. The actual assessment policy regulation in Portugal states that teachers should certify their students' knowledge at the end of each trimester for parents, students, and the school (Decreto-Lei 55/2018). This purpose was also mentioned a few times in teachers' conceptions. It is clear that assessment in Portugal involves a relationship between formative and summative purposes, with an evident emphasis on improvement for learning and teaching. So, it is understandable that teachers think assessment should inform teachers about the changes they have to implement in teaching, and should inform students about their strengths and weaknesses and help them reorganize their learning in the future. But why, then, do teachers not implement more formative assessment? We can presume that the teachers' conceptions reflect the obligations of the National Policy on Assessment in primary schools in Portugal (the emphasis is on formative assessment). However, the constraints imposed by the context on the materialization of teachers' assessment conceptions (Opre, 2015) can result in disparities between conceptions and practices.

An additional possible explanation for such discrepancy is the historical context of assessment in Portugal. The certification of students was the main assessment purpose during recent years (2011-2016): in this period, examinations proliferated at all levels of schooling, with various consequences for teachers and students. We believe that, despite new regulations, the current assessment practices of these teachers are still embedded in the 
assessment purposes that dominated the assessment system until recently-the purposes of student and school accountability.

It is also possible to explain the discrepancies between conceptions and practices through the pressures of high-stakes assessments on teachers' work (Brown et al., 2009a). Although, since 2016, there has not been a national maths exam at the end of the fourth grade of schooling in Portugal, national tests are still held in the second, fifth, and eighth grades. These exams are intended to detect students' difficulties in these middle grades and help teachers find strategies that help them overcome these difficulties in the following years. However, results serve a range of purposes, including evaluative feedback to teachers, schools, and the national system about the effectiveness of students' performance. These results also serve to advise teachers and parents about decisions on future study strategies (Despacho normativo 1-F/2016 de 5 de abril, 2016). When we interviewed these teachers, their students were in the third grade, some months after having performed those exams. We can suppose that this type of assessment has an effect on these teachers' assessment practices and on these students' conceptions, which reinforces the accountability purpose of assessment.

Finally, another factor to take into account when evaluating teachers' conceptions is the fact that they may have given socially desirable responses that differ from what they actually do in the classroom. When faced with questions about assessment, which can be a sensitive topic for them, teachers may answer in accordance with what they believe is socially expected (Eivarsen and Valand, 2010). These concerns may remain, even though participants were repeatedly assured of confidentiality and several strategies were adopted to reduce social desirability bias (Ananthram, 2016): for example, teachers themselves volunteered to participate in the interview, they remained anonymous, and we provided a brief overview of the study goals.

What we can infer here is that the relationship between conceptions and practices is complex, and that individual, social, and contextual factors could influence one another with implications for teaching and learning. We can also assume that, in some circumstances, teachers' assessment practices are closer to students' conceptions of assessment (Opre, 2015) than to their own conceptions. The outcomes showed that these young students perceived assessment mostly in the form of a grade: this view of assessment can bring some obstacles to an assessment conception that mediates their learning and achievement, and can have consequences for how they involve themselves in assessment tasks. According to Black and Wiliam (2018), assessment supports learning when students receive feedback that takes learning forward. In our study, we observed that in several situations teachers provided evaluative, general, written, and oral feedback, frequently focusing on results that reinforced students' conceptions of AoL. So, assessment, in terms of students' conceptions and teachers' practices, is intended to serve both certification and improvement of teaching and learning, but priority is given to student and school accountability.

In four of the cases presented, teachers' practices and conceptions seem to be generally inconsistent. Cognitive dissonance theory (Festinger, 1957) suggests that individuals seek to maintain consonance among multiple cognitions of beliefs and behavior. The theory adds that if there is dissonance between beliefs and behavior, "individuals engage in changing their beliefs and/or behaviors to make them consonant in order to achieve cognitive consistency" (Guerra and Wubbena, 2017, p. 39). Therefore, to reduce the dissonance observed in the present research, we think that teachers need to focus primarily on enacting changes in their practices rather than changes in beliefs. When applied to the present study, we suppose that teachers' belief-practice inconsistency is likely to be related to the policy context of a high-stakes test-influenced environment. The intense pressure upon teachers comes from focusing only on high-stakes testing and, in some circumstances, can lead to burnout (Pishghadam et al., 2014). Although the existing literature reinforces that beliefs shape teacher behavior (Karaagac and Threlfall, 2004), in the present research, it seems that the teachers' goals drove their behavior more than their beliefs did.

If teachers are not motivated to change their classroom assessment practices, the conflict with their beliefs will remain evident, though the teachers were aware of that inconsistency, as it was stated by some of them. It may be expected that those teachers who considered assessment inaccurate, neglected, or unfair may become indifferent and unmotivated toward their learners and their profession (Pishghadam et al., 2014). Additionally, teacher burnout can reduce students' intrinsic motivation, which may reduce learning (Shen et al., 2015).

Our results tend to confirm Remesal's (2009, p.49) hypothetical model that "young pupils perceive assessment practices, whichever form they take." From an interpretivist approach, it is important to recognize the complexity of interactions among students, teachers, and assessment (Gipps, 1999). Students' views of assessment are conceptualized and reconstructed through their experiences within the social setting of the classroom. So, individual factors such as the learner's expectations of the classroom process, their interpretation of the demands of the task, and the criteria for success are in constant relationship with social factors such as teachers' expectations and their pedagogical practices. Hence, if assessment practices are associated mostly with learning certification, students may develop a more passive role in their learning process (Remesal, 2009).

\section{Final Considerations and Educational Implications}

Our most striking finding was that the assessment practices in the study context were mostly traditional (summative) and that most academics described the purpose of assessment in a dialogical way, emphasizing formative assessment and the importance of feedback for learning or to modify teaching strategies and adapt them to students' specific needs.

In order to promote significant learning in these students, we think it is necessary to introduce changes that make their teachers' assessment practices authentic and more formative, consonant with their conceptions. Our results indicate that assessment practices change slowly. The ways of thinking (in 
line with the legislation on student assessment) and practising differ in teachers. Therefore, we suggest that if we want a more dialogical teaching and learning process, more specific research in real assessment contexts is needed to understand teachers' assessment practices. We suggest that the development of assessment practices could be supported through more collaborative practices of assessment. Sharing positive experiences of assessment in collaborative settings may result in higher awareness of the relationship between assessment conceptions and practices (Siarova et al., 2017).

Thus, if learning is socially situated, the role of teachers in analyzing and reflecting on the needs of their students requires that emphasis be placed on formative assessment of pupils' understanding. So, it is important that teachers and students come to a common understanding of the meaning of communicated feedback in order for students to understand how to improve their achievement (Gipps, 1999; Andersson, 2016). In this sense, newer practices of assessment, deriving from the socio-cultural approach, are required. The assessment task should highlight how the learning process is developing, and has to be understood as an interactive, dynamic, and collaborative task (with the teacher and with the peer group) in order to develop students as self-regulated learners (Gipps, 1999).

\section{DATA AVAILABILITY STATEMENT}

The raw data supporting the conclusions of this article will be made available by the authors, without undue reservation.

\section{REFERENCES}

Ämmälä, A., and Kyrö-Ämmälä, O. (2018). Conceptions of school assessment: what do Finnish elementary school students think of assessment? Educ. North 25 (1-2), 275-294. doi:10.26203/0g1s-hf54. Available at: https://www.abdn.ac. uk/education/research/eitn/journal/558/ (Accessed September 11, 2019).

Ananthram, S. (2016). "HRM as strategic business partner: the contributions of strategic agility, knowledge management and management development in multinational enterprises - empirical insights from India," in Asia Pacific human resource management and organizational effectiveness. Editors A. Nankervis, C. Rowley, and N. M. Salleh (London, United Kingdom: Elsevier), 87-109. doi:10.1016/B978-0-08-100643-6.00005-1

Andersson, N. (2016). Teacher's conceptions of quality in dance education expressed through grade conferences. J. Pedagogy 7 (2), 11-32. doi:10.1515/ jped-2016-0014

Azis, A. (2012). Teachers' conceptions and use of assessment in student learning. Indones. J. Appl. Ling. 2 (1), 41-45. doi:10.17509/ijal.v2i1.72

Azis, A. (2015). Conceptions and practices of assessment: a case of teachers representing improvement conception. TEFLIN J. 26 (2), 129-154. doi:10. 15639/teflinjournal.v26i2/129-154

Barnes, N., Fives, H., and Dacey, C. M. (2015). "Teachers' beliefs about assessment," in International handbook of research on teachers' beliefs. Editors H. Fives and M. G. Gill (New York, NY: Routledge), 284-300.

Barnes, N., Fives, H., and Dacey, C. M. (2017). U.S. teachers' conceptions of the purposes of assessment. Teach. Teach. Educ. 65, 107-116. doi:10.1016/j.tate. 2017.02.017

Black, P., and Wiliam, D. (2018). Classroom assessment and pedagogy. Assess. Educ. Principles, Policy Pract. 5 (1), 7-74. doi:10.1080/0969594X.2018.1441807

Borko, H., Mayfield, V., Marion, S., Flexer, R., and Cumbo, K. (1997). Teachers' developing ideas and practices about mathematics performance assessment:

\section{ETHICS STATEMENT}

The studies involving human participants were reviewed and approved by the Ethics Committee of ISPA. Written informed consent to participate in this study was provided by the participants' legal guardian/next of kin.

\section{AUTHOR CONTRIBUTIONS}

All authors listed have made a substantial, direct, and intellectual contribution to the work and approved it for publication.

\section{FUNDING}

This study was supported by the FCT - Science and Technology Foundation - PTDC/MHC-CED/1680/2014 and UIDP/04853/ 2020

\section{ACKNOWLEDGMENTS}

We wanted to say thank you to Marta Gomes and Cristina Sanches for their contributions to this project. It was helpful to have someone with whom to discuss ways of fine-tuning and optimizing our processes. Our sincere thanks for your invaluable assistance.

successes, stumbling blocks, and implications for professional development. Teach. Teach. Educ. 13 (3), 259-278. doi:10.1016/s0742-051x(96)00024-8

Brown, G. T. L. (2004). Teachers' conceptions of assessment: implications for policy and professional development. Assess. Educ. Principles, Policy Pract. 11 (3), 301-318. doi:10.1080/0969594042000304609

Brown, G. T. L. (2008). Conceptions of assessment: understanding what assessment means to teachers and students. New York, NY: Nova Science Publishers.

Brown, G. T. L. (2011). Teachers' conceptions of assessment: comparing primary and secondary teachers in New Zealand. Assess. Matters 3, 45-70. doi:10.18296/ am.0097

Brown, G. T. L., and Harris, L. (2012). Student conceptions of assessment by level of schooling: further evidence for ecological rationality in belief systems. Aust. J. Educ. Dev. Psychol. 12, 46-59.

Brown, G. T. L., and Hirschfeld, G. H. F. (2007). Students' conceptions of assessment and mathematics: self-regulation raises achievement. Aust. J. Educ. Dev. Psychol. 7, 63-74.

Brown, G. T. L., Irving, S. E., Peterson, E. R., and Hirschfeld, G. H. F. (2009a). Use of interactive-informal assessment practices: New Zealand secondary students' conceptions of assessment. Learn. Instr. 19 (2), 97-111. doi:10.1016/j. learninstruc.2008.02.003

Brown, G. T. L., Kennedy, K. J., Fok, P. K., Chan, J. K. S., and Yu, W. M. (2009b). Assessment for student improvement: understanding Hong Kong teachers' conceptions and practices of assessment. Assess. Educ. Principles, Policy Pract. 16 (3), 347-363. doi:10.1080/09695940903319737

Brown, G. T. L., Lake, R., and Matters, G. (2011). Queensland teachers' conceptions of assessment: the impact of policy priorities on teacher attitudes. Teach. Teach. Educ. 27 (1), 210-220. doi:10.1016/j.tate.2010.08.003

Brown, G. T. L., and Remesal, A. (2017). Teachers' conceptions of assessment: comparing two inventories with Ecuadorian teachers. Stud. Educ. Eval. 55, 68-74. doi:10.1016/j.stueduc.2017.07.003 
Buehl, M. M., and Beck, J. S. (2015). "The relationship between teachers' beliefs and teachers' practices," in International handbook of research on teachers' beliefs. Editors H. Fives and M. G. Gill (New York, NY: Routledge), 65-84.

Carless, D. (2009). "Learning-oriented assessment: principles, practice, and a project," in Tertiary assessment and higher education student outcomes: policy, practice, and research. Editors L. H. Meyer, S. Davidson, H. Anderson, R. Fletcher, P. M. Johnston, and M. Rees (Wellington, New Zealand: Ako Aotearoa \& Victoria University of Wellington), 79-90.

Cizek, G. J. (2010). "An introduction to formative assessment: history, characteristics, and challenges," in Handbook of formative assessment. Editors H. L. Andrade and G. J. Cizek (Oxon, United Kingdom: Taylor \& Francis), 3-17.

Cohen, L., Manion, L., and Morrison, K. (2008). Research methods in education. London, United Kingdom: Routledge.

Decreto-Lei 55/2018 de 6 de julho (2018). Diário da República no 129/2018, 1. ${ }^{\text {a }}$ série. Available at: https://data.dre.pt/eli/dec-lei/55/2018/07/06/p/dre/pt/html (Accessed July 06, 2018).

Despacho normativo 1-F/2016 de 5 de abril (2016). Diário da República no 66/ 2016, 2. ${ }^{\text {a }}$ série. Available at: https://dre.pt/application/conteudo/74059570 (Accessed April 05, 2016).

Dixson, D. D., and Worrell, F. C. (2016). Formative and summative assessment in the classroom. Theory into Pract. 55 (2), 153-159. doi:10.1080/00405841.2016. 1148989

Eivarsen, K., and Våland, T. I. (2010). "From research question to research design: challenges of obtaining valid sensitive data," in Paper presented at the 26th industrial marketing and purchasing group, Budapest, Hungary (IMP Group). 2-4. September, 2010, 1-13. Available at: http://www.impgroup.org/uploads/ papers/7508pdf (Accessed September 11, 2014).

Etikan, I., Musa, S. A., and Alkassim, R. S. (2016). Comparison of convenience sampling and purposive sampling. Am. J. Theor. Appl. Stat. 5 (1), 1-4. doi:10. 11648/j.ajtas.20160501.11

Festinger, L. (1957). A theory of cognitive dissonance. Stanford, CA: Stanford University Press.

Fletcher, R. B., Meyer, L. H., Anderson, H., Johnston, P., and Rees, M. (2012). Faculty and students conceptions of assessment in higher education. High. Educ. 64 (1), 119-133. doi:10.1007/s10734-011-9484-1

Gipps, C. (1999). Socio-cultural aspects of assessment. Rev. Res. Educ. 24, 355-392. doi:10.2307/1167274

Guerra, P. L., and Wubbena, Z. C. (2017). Teacher beliefs and classroom practices cognitive dissonance in high stakes test-influenced environments. Issues Teach. Educ. 26 (1), 35-51. Available at: https://files.eric.ed.gov/fulltext/ EJ1139327.pdf (Accessed March 9, 2019).

Harris, L. R., and Brown, G. T. L. (2009). The complexity of teachers' conceptions of assessment: tensions between the needs of schools and students. Assess. Educ. Principles, Policy Pract. 16 (3), 365-381. doi:10.1080/09695940903319745

Hattie, J. (2012). Visible learning for teachers maximizing impact on learning. New York, NY: Routledge.

Hattie, J., and Timperley, H. (2007). The power of feedback. Rev. Educ. Res. 77, 81-112. doi:10.3102/003465430298487

James, M., and Pedder, D. (2006). Beyond method: assessment and learning practices and values. Curric. J. 17 (2), 109-138. doi:10.1080/ 09585170600792712

Karaagac, M. K., and Threlfall, J. (2004). "The tension between teacher beliefs and teacher practice: the impact of the work setting," in Proceedings of the 28th conference of the international group for the psychology of mathematics education. Editors M. J. Høines, A. B. Fuglestad., Bergen, Norway, July 14-18, 2004, Vol. 3, 137-144. Available at: http://emis.impa.br/EMIS/ proceedings/PME28/RR/RR276_Karaagac.pdf. (Accessed April 9, 2019).

Miles, M. B., Huberman, A. M., and Saldaña, J. (2014). Qualitative data analysis. a methods sourcebook. 3rd Edn. Thousand Oaks, CA: Sage.

Mullis, I. V. S., and Martin, M. O. (2015). TIMSS 2015. assessment frameworks. Chestnut Hill, MA: Chestnut HillTIMSS \& PIRLS International Study Center.

Nortvedt, G. A., Santos, L., and Pinto, J. (2016). Assessment for learning in Norway and Portugal: the case of primary school mathematics teaching. Assess. Educ. Principles, Policy Pract. 23 (3), 377-395. doi:10.1080/0969594x.2015.1108900

Opre, D. (2015). Teachers' conceptions of assessment. Procedia-Social Behav. Sci. 209, 229-233. doi:10.1016/j.sbspro.2015.11.222
Organisation for Economic Co-operation and Development, OECD (2008). "Assessment for learning. formative assessment," in Paper presented at the OECD/CERI international conference learning in the 21st century: research, innovation and policy (Paris, France: OECD Publishing). Available at: https:// www.oecd.org/site/educeri21st/40600533.pdf. (Accessed April 9, 2019).

Organisation for Economic Co-operation and Development, OECD (2016). PISA 2015 results (volume I): excellence and equity in education. Paris, France: OECD Publishing.

Pishghadam, R., Adamson, B., Sadafian, S. S., and Kan, F. L. F. (2014). Conceptions of assessment and teacher burnout. Assess. Educ. Principles, Policy Pract. 21 (1), 34-51. doi:10.1080/0969594x.2013.817382

Rahman, M. S. (2017). The advantages and disadvantages of using qualitative and quantitative approaches and methods in language "testing and assessment" research: a literature review. J. Educ. Learn. 6 (1), 102-112. doi:10.5539/jel. v6n1p102

Remesal, A. (2006). Los problemas en la evaluación del aprendizaje matemático en la educación obligatoria: perspectiva de profesores y alumnos [Problems in the evaluation of mathematical learning in compulsory education: perspective of teachers and students]. Doctoral dissertation: Universitat de Barcelona, Departament de Psicologia Evolutiva i de l'Educació, Barcelona. Available at: http://hdl.handle.net/10803/2646 (Accessed April 12, 2011).

Remesal, A. (2007). Educational reform and primary and secondary teachers' conceptions of assessment: the Spanish instance, building upon Black and Wiliam (2005). Curric. J. 18 (1), 27-38. doi:10.1080/09585170701292133

Remesal, A. (2009). "Spanish students teachers' conceptions of assessment when starting their career," in Paper presented at the symposium perceptions and conceptions of assessment in the classroom: different national perspectives, Amsterdam, Netherlands, August 25-29, 2009 (EARLI), 1-11. Available at: http://www.ub.edu/grintie. (Accessed April 11, 2019).

Remesal, A. (2011). Elementary and secondary teachers' conceptions of assessment: a qualitative study. Teach. Teach. Educ. 27 (2), 472-482. doi:10. 1016/j.tate.2010.09.017

Santos, L. (2004). "O ensino ea aprendizagem da matemática em Portugal: Um olhar através da avaliação," in Investigación en educación matemática: octavo Simposio de la Sociedad Española de Investigación en Educación Matemática (SEIEM): a Coruña, septiembre 9-11, 2004 (Servizo de Publicacións), 127-154.

Shen, B., McCaughtry, N., Martin, J., Garn, A., Kulik, N., and Fahlman, M. (2015). The relationship between teacher burnout and student motivation. Br. J. Educ. Psychol. 85 (4), 519-532. doi:10.1111/bjep.12089

Siarova, H., Sternadel, D., and Masidlauskaite, R. (2017). Assessment practices for 21 st century learning: review of evidence. NESET II report. Luxembourg, Europe: Publications Office of the European Union. doi:10.2766/71491

Singh, C. K. S., Lebar, O., Kepol, N., Rahman, R. A., and Mukhtar, K. A. M. (2017). An observation of classroom assessment practices among lecturers in selected Malaysian higher learning institutions. Malaysian J. Learn. Instr. 14 (1), 23-61. doi:10.32890/mjli2017.14.1.2. Available at: https://files.eric.ed.gov/fulltext/ EJ1150557.pdf. (Accessed October 13, 2019).

Suurtamm, C., Koch, M., and Arden, A. (2010). Teachers' assessment practices in mathematics: classrooms in the context of reform. Assess. Educ. Principles, Policy Pract. 17 (4), 399-417. doi:10.1080/0969594x.2010.497469

Vandeyar, S., and Killen, R. (2007). Educators' conceptions and practice of classroom assessment in post-apartheid South Africa. South Afr. J. Educ. 27 (1), 101-115. Available at: https://files.eric.ed.gov/fulltext/EJ1150092.pdf. (Accessed April 10, 2019).

Conflict of Interest: The authors declare that the research was conducted in the absence of any commercial or financial relationships that could be construed as a potential conflict of interest.

Copyright (c) 2021 Monteiro, Mata and Santos. This is an open-access article distributed under the terms of the Creative Commons Attribution License (CC $B Y)$. The use, distribution or reproduction in other forums is permitted, provided the original author(s) and the copyright owner(s) are credited and that the original publication in this journal is cited, in accordance with accepted academic practice. No use, distribution or reproduction is permitted which does not comply with these terms. 